\title{
SOCIOLOGY IN THE ECONOMIC MODE
}

\begin{abstract}
A Review Essay on James Coleman, Foundations of Social Theory, The Belknap Press of Harvard University Press, 1990.
\end{abstract}

There is a wide gap between two branches of sociological investigations. Social theory, on the one hand, has ever since its origin been directed towards the study of the social system as a whole. Empirical research in sociology, on the other hand, has largely focused upon individual behaviour and the consequences of certain changes at the system level on this behaviour. According to Coleman, this is due to the fact that observations are usually made at the level of individuals. This state of affairs is unsatisfactory for theoretical as well as practical reasons. Focusing on the practical reasons, and admitting that sociological knowledge should be useful to guide policy interventions, we have to face two facts. First, policy makers are mainly interested in the consequences of a certain policy measure on the social system as a whole. Second, most policy measures are effective at the individual level and policy makers attempt to influence individual behaviour in such a way that the desired consequences at the system level are achieved. From this perspective both theoretical and empirical research in sociology are defunct. Traditional social theory is not useful to guide policy interventions, because it tends to neglect the fact that individuals mediate between policy measures and system-wide consequences of those policy measures. Empirical research that focuses on individual behaviour is not useful, because the system-wide consequences of the interactions between individuals are not studied. What is needed is a type of social research in which the system wide consequences of changes in the social system are studied with individual behaviour performing the role of mediator: the gap between social theory and empirical research in sociology has to be closed.

The closing of this gap is the main target of James Coleman's 
The closing of this gap is the main target of James Coleman's Foundations of Social Theory. This magnum opus really is a significant book in many respects. It delves into the philosophical foundations of sociology, it discusses relations between sociology and other social sciences, it treats theoretical and empirical issues, it gives a formal and nonformal analysis of many ideas, and moreover, it contains quite a few nice examples in which the general theme of the book is illustrated. The present review can only deal with a very limited number of these points. In the following I will concentrate on three important elements of the book. First, I will discuss the version of methodological individualism (MI) that Coleman endorses. Second, I will go into the method Coleman regards as the most appropriate from the perspective of MI, namely the economic method of general equilibrium analysis. Finally, I will spend some time on the issue of normative versus positive theory. Along the way I will introduce the reader to some of the examples Coleman uses. At points I will make some critical remarks on the content of the book. This should not be regarded as a way to belittle what Coleman has accomplished, but rather as a warning that there is still a long way to go before the gap is closed.

\section{METHODOLOGICAL INDIVIDUALISM}

From the above introduction it will be clear that Coleman tries to build a bridge between social theory and social research that can be useful for policy interventions. It is also clear that this bridge should allow for two transitions, namely one (the macro-to-micro transition) from the system level to the level of individual behaviour and the other (the micro-to-macro transition) from the level of individual behaviour back to the system level. As an example of how the two transitions can be conceptualized, consider Max Weber's study on the relation between a protestant religious doctrine and the origin of capitalism. Coleman (pp. 6-10) analyses this example by means of Figure 1. The figure shows that the direct relation between the system-wide phenomena 'Calvinism' and 'capitalism' is an emergent one. It 'really' is a consequence of the relations indicated by arrows 1,2 and 3 . Arrow 1 depicts the macro-to-micro transition: protestant religion generates 


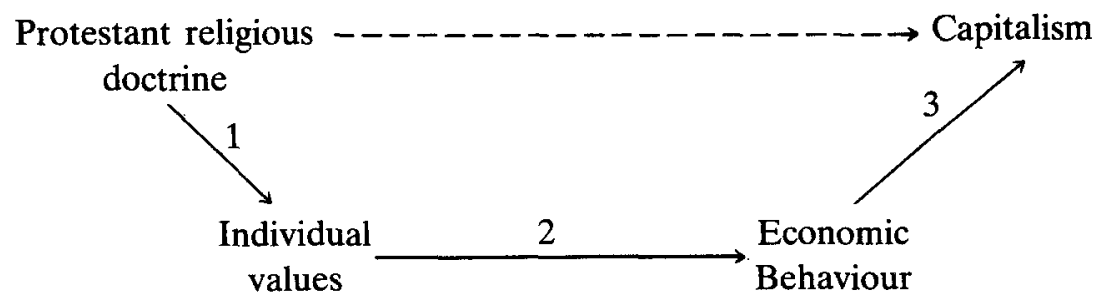

Fig. 1.

certain values in individuals who adhere to the religion. Arrow 2 says that individuals with certain values are more likely to show a particular kind of economic behaviour. Arrow 3 depicts the micro-to-macro transition: the interaction of individuals who behave in a certain economic way helps to bring about a capitalistic organization form in society. The micro-to-macro transition then is the main problem in many of the social sciences (see also the critique of empirical research in sociology above). It is, Coleman argues, also the main weakness of Weber's account of the rise of capitalism.

To illustrate the claim that the micro-to-macro transition really is a main problem in social science and to come back to the major deficiency of much empirical research that is done, consider the policy measure of providing job training for black youth in order to decrease unemployment (see Coleman, pp. 642-645 and the references given there). Empirical research has shown that there is some evidence for the statement that enrollment in job training programs increases the individual's probability of being employed. Clearly, unemployment in society will decrease only if a new job is created or a vacant job filled. It will not decrease if the trained individual replaces someone else. However, there is hardly any research showing whether or not somebody is replaced and, thus, the research that has been done does not give guidance for policy intervention.

The above two examples also show what form of MI Coleman has in mind. It is a form in which individual behaviour is affected by the social environment in which the individual is situated, and it is also a form that allows relationships at the system level to be quite dissimilar from relationships at the individual level. It is also not denied that correlations exist at the system level, but what is denied is that an 
explanation of such a correlation can be given without reference to individual behaviour. This is a very weak form of MI (especially when taking into account the fact that Coleman has a broad view of the notion of an individual; see below) and it is mainly argued for on the grounds that, in sociology, data on individual behaviour are more readily available and that the relationships that prove to be consistent with MI are more stable ('autonomous') against policy interventions than relations at the system level. Another reason Coleman mentions for requiring that a theory be consistent with $\mathrm{MI}$ is that in such a theory the fundamental problems of moral and political philosophy concerning the relation between man and society can be raised. This cannot be said for much of what goes under the name of social theory. Before discussing the method Coleman actually uses, two elements of Coleman's version of MI should be emphasized. First, we have not yet specified who can be considered as 'individuals' in the social system and, second, we have yet not said what theory of individual behaviour is considered.

With respect to the question of who can be considered as individuals' in a theory about social systems Coleman takes a pragmatic attitude. He introduces the notion of an 'actor', which he regards as a human body or some kind of organization or institution that has interests, resources and the right to control these resources. This definition means that what can be regarded as an actor is closely related to what type of agents are distinguished by the law, because property rights determine which property belongs to whom and also who has the right to decide how this property will be used. Note, then, that the law in many modern societies regards, for example, firms and (local) governments as actors. Also, if we are interested in the consequences of certain system-wide policy interventions it is often useful to regard firms and governments as the basic units of analysis because it is on these units that the policy is supposed to have an effect. (In fact, Coleman devotes a large part of his book (pp. $531-650)$ to Modern Society in which he argues that the notion of a 'corporate actor' is what distinguishes modern society from more traditional societies.) Finally, observe that the notions of 'individual' and 'system' are relative to each other: If we consider a firm as the system in a particular study, then we cannot take the firm to be the individual in that system as well. 
The theory of individual behaviour that is invoked is that of a purposeful actor and often a simple utility maximization under constraints is used. Now, Coleman immediately admits that certain actions are better described in other ways (p. 15). Nevertheless, he sticks to it and again, largely for pragmatic reasons. One reason is to be able to fit sociological discourse better into the discourse of other political and social sciences in which the model of purposive action is frequently used. A reason to use maximization of utility is its simplicity, which is highly desirable due to the complexities that are most likely to arise in the macro-to-micro and the micro-to-macro transitions. A 'deeper' argument is that many social theorists construct their theories with a purpose in mind. An inconsistency arises if these theories themselves are based on non-purposive actors, because the purposeful social theorist himself is part of the social system in which he is an actor. Of course, this argument depends on the assumption that the theorist is right in believing that he constructs theories purposefully.

\section{GENERAL EQUILIBRIUM ANALYSIS}

So far, we have sketched the general approach in which Coleman's work has to be considered. I largely agree with this approach and think that it is powerful enough to yield quite a few interesting insights. When it comes to the method Coleman regards as the most appropriate method that is in line with MI and in which issues such as the ones considered above can be studied, he chooses the economic method of perfectly competitive general equilibrium analysis. The last part of the book (pp. 667-932), in which nonformal arguments are formalized by means of mathematics is, in fact, largely based on this competitive model.

In the general equilibrium model agents have endowments and preferences over consumption bundles. They exchange commodities in order to achieve a higher utility level. In equilibrium, prices (emergent phenomena) are identical for each pairwise exchange. Equilibria are Pareto efficient. Coleman interprets the endowments as resources and the value of those resources as the power of an individual actor. He works exclusively with Cobb-Douglas utility functions and the parameters of these functions are interpreted as the interest of a particular actor in that particular commodity. Accordingly, he has given an 
interpretation to the concept of an actor in this particular model. To the present reviewer the restriction to the Cobb-Douglas case seems to be unduly restrictive. It is well known for its simplicity, but also for its specificity. In particular, there are no cross-effects from one market to the other. It remains to be seen whether or not the results Coleman derives depend crucially on this specification.

With this competitive model he analyzes such issues as trust, power and norms (pp. 747-829). Let us take trust as an example to illustrate the type of exchange Coleman is concerned with. An actor, the trustor, who places trust in another actor, the trustee, gives up something with certainty in order to receive something he prefers, but with a risk that he won't get it. The trustor will only engage in the exchange if his expected gain is higher than the loss with certainty. The trustee, on the other hand, will prove to be trustworthy if the negative impact of proving not to be trustworthy (due to reputation effects which may harm him in the future) outweighs the immediate gain. Coleman introduces a probability, $p$, that the trust will be justified in the competitive model and show that the resulting equilibrium is more efficient the higher $p$ is.

The validity of general equilibrium analysis depends crucially on a belief in the functioning of the market system. Many of the issues Coleman considers are discussed in terms of (social) exchange. For example, in discussing the one-shot Prisoner's Dilemma (pp. 204-205, and 253) Coleman argues that the cooperative outcome can easily be sustained by rational behaviour (i.e., without a norm) by setting up a 'market' in which rights to control actions are exchanged. Obviously, in the Prisoner's Dilemma everyone has an interest in controlling the other's actions and if everyone has the right to control someone else's action, then the cooperative outcome will result as a consequence of rational behaviour on the part of the actors. Of course, in a small community in which people can easily communicate with each other and in which it is legally allowed to exchange rights to determine someone else's action, Coleman's suggestion seems to be very smart. There is, of course, a question here whether his solution should be regarded as part of a positive or normative theory of social interaction. This issue will be dealt with in the next section. The issue that should concern us here is whether Coleman's suggestion can also be effective when a society as a whole faces a Prisoner's Dilemma situation. 
The general equilibrium model is meant to represent a world in which every individual actor is small relative to the society as a whole. In such a world it is very likely that the individual actor does not have an incentive to set up a market for exchange. A complete system of markets has to exist beforehand. The main difficulty of general equilibrium theory, then, is that if everyone takes the exchange rates as given, then from an individualistic point of view it is not clear how exchange rates come about. Economics textbooks allude to an auctioneer (or central clearing house) who determines prices, but in real markets - in which no auctioneer exists - the introduction of an auctioneer seems to be just an illegitimate short-cut for saying that the system as a whole determines prices. Another way to 'solve' this problem is to introduce a law of demand and supply, but the individualistic foundations for this law are largely unexplored. Thus, from the point of view of MI there are severe problems with the way the general equilibrium model accounts for exchange rates. In order to do justice to Coleman I should note that he himself mentions some of the above problems when he notices that it is unlikely that there is a double coincidence of wants and when he observes that "in much of the economic literature on the perfectly competitive market, the institutional and social-structural assumptions remain implicit" ( $p$. 686). The modifications to the model of perfect competition that he promises to give (p. 687) do not deal in a fully adequate way with the abovementioned issues, however.

What this critique all amounts to is that I do not see very good reasons why Coleman has taken the perfectly competitive model as his point of reference. In my view it is more natural to take noncooperative game theory as a point of reference, especially given the view of MI outlined above. On pp. 11-12 Coleman himself sketches the components of such a game-theoretic approach and he discusses how the macro-to-micro and the micro-to-macro transitions find a natural place in such an approach. In noncooperative game theory one has to specify the roles of the players and their goals (interests). Furthermore, one has to specify what actions each player is allowed to take. Finally, rules have to be specified which state the consequences of each player's action for other players in the game. The rules of the game taken together specify the macro-to-micro transition, because the action the individual actor takes depends on the (social) rules of the 
game. The micro-to-macro transition is mirrored in the way the actions combine with each other. The noncooperative game theoretic approach is thus very much in line with $\mathrm{MI}$ and its main advantage (relative to the general equilibrium model) is that there is no need to introduce a dubious concept as the auctioneer for the micro-to-macro transition to be accomplished.

\section{NORMATIVE OR POSITIVE THEORY}

Above, we have encountered the issue whether Coleman's suggestion to solve the Prisoner's Dilemma is a normative or a positive one. In this last section I will delve further into this issue.

It is well known that positive and normative interpretations of the notion of rational behaviour coexist. It is not my intention here to take a position on this issue, but instead I will stress the relevance of this discussion for Coleman's enterprise. At some points it is not clear whether Foundations of Social Theory gives foundations for positive or normative theory. Besides the discussion on the Prisoner's Dilemma mentioned above, positive and normative considerations intermingle when Coleman discusses social choice theory and the relation between social theory and political philosophy.

When dealing with social choice theory (pp. 371-421) Coleman mentions that, from a methodological individualistic point of view, it is not surprising that the axiom of independence of irrelevant alternatives does not hold when social choice is based on majority voting. The example he gives is about the election of a candidate in the Democratic mayoral primary in Chicago in 1983 (pp. 400-402). First, there were two candidates $-\mathrm{a}$ black and a white - and in the polls the white candidate came out ahead. When a second white candidate entered the race, the black candidate won the elections. This phenomenon can easily be explained by the fact that voting was largely along racial lines. The axiom of independence of irrelevant alternatives does not have to be violated at the individual level. Coleman goes on to study the characteristics of different voting procedures (as Borda elimination and Condorcet's procedure). So far, this analysis can be regarded as part of a positive theory of how choices are made in societies which are governed by different voting procedures. But then, in summarizing the 
results, he observes that having gone through several steps one is lead in the direction of a good procedure (p. 413) so that a normative element has slipped into the discussion.

The second case in which the distinction between normative and positive theory is not very sharp is when discussing the relation between social theory and political philosophy. On p. 41 Coleman is quite explicit about the normative aspirations of his theory. $\mathrm{He}$ considers the general equilibrium model and concludes that in this model attributing utility functions to individual agents made it possible to base normative statements on this model (cf. Rawls and Nozick, among others). Following a standard argument in welfare economics, one of the reasons for using utility maximization in social theory is to have the potential to make such normative statements based on the theory. On pp. 344-345, on the other hand, Coleman notes that the devices (such as the veil of ignorance) used by political philosophers have a major drawback when it comes to positive social theory, namely that they are based on patently false assumptions. It is, for example, not true that each person is totally ignorant about his future possibilities. Moving to positive social theory, then, entails - according to Coleman-removing this false assumption from the theory. Due to space limitations I can only note that this position presupposes that the difference between positive and normative theory relates to the issue of the descriptive adequacy of the assumptions and that the other assumptions made, notably the assumption that individuals behave rationally, are descriptively adequate. Both presuppositions seem to be debatable.

Erasmus University, Rotterdam, The Netherlands. 